\title{
Changes in African Elephant (Loxodonta africana) faecal steroid concentrations post-defaecation
}

\begin{tabular}{|c|c|}
\hline \multicolumn{2}{|c|}{$\begin{array}{l}\text { Authors: } \\
\text { Judith T. Webber }^{1} \\
\text { Michelle D. Henley }^{2,3} \\
\text { Yolanda Pretorius }^{1,4} \\
\text { Michael J. Somers }^{1,5} \\
\text { Andre Ganswindt }^{5,6}\end{array}$} \\
\hline \multicolumn{2}{|c|}{$\begin{array}{l}\text { Affiliations: } \\
{ }^{1} \text { Centre for Wildlife } \\
\text { Management, Department of } \\
\text { Animal and Wildlife Sciences, } \\
\text { University of Pretoria, } \\
\text { South Africa }\end{array}$} \\
\hline $\begin{array}{l}{ }^{2} \text { Applied Beha } \\
\text { and Ecosysten } \\
\text { Unit, School o } \\
\text { Sciences, Univ } \\
\text { South Africa, }\end{array}$ & $\begin{array}{l}\text { vioural Ecology } \\
\text { Research } \\
\text { f Environmental } \\
\text { ersity of } \\
\text { outh Africa }\end{array}$ \\
\hline \multicolumn{2}{|c|}{$\begin{array}{l}{ }^{3} \text { Elephants Alive, Hoedspruit, } \\
\text { South Africa }\end{array}$} \\
\hline \multicolumn{2}{|c|}{$\begin{array}{l}{ }^{4} \text { Southern African Wildlife } \\
\text { College, Hoedspruit, } \\
\text { South Africa }\end{array}$} \\
\hline \multicolumn{2}{|c|}{$\begin{array}{l}{ }^{5} \text { Mammal Research Institute, } \\
\text { Department of Zoology and } \\
\text { Entomology, University of } \\
\text { Pretoria, South Africa }\end{array}$} \\
\hline \multicolumn{2}{|c|}{$\begin{array}{l}{ }^{6} \text { Endocrine Research } \\
\text { Laboratory, Department of } \\
\text { Anatomy and Physiology, } \\
\text { University of Pretoria, } \\
\text { South Africa }\end{array}$} \\
\hline \multicolumn{2}{|c|}{$\begin{array}{l}\text { Corresponding author: } \\
\text { Andre Ganswindt, } \\
\text { andre.ganswindt@up.ac.za }\end{array}$} \\
\hline \multicolumn{2}{|c|}{$\begin{array}{l}\text { Dates: } \\
\text { Received: } 15 \text { Oct. } 2017 \\
\text { Accepted: } 03 \text { Apr. } 2018 \\
\text { Published: } 12 \text { June } 2018\end{array}$} \\
\hline \multicolumn{2}{|l|}{ Read online: } \\
\hline 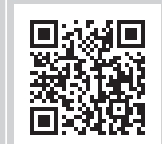 & $\begin{array}{l}\text { Scan this QR } \\
\text { code with your } \\
\text { smart phone or } \\
\text { mobile device } \\
\text { to read online. }\end{array}$ \\
\hline
\end{tabular}

Background: Faecal hormone metabolite measurement is a widely used tool for monitoring reproductive function and response to stressors in wildlife. Despite many advantages of this technique, the delay between defaecation, sample collection and processing may influence steroid concentrations, as faecal bacterial enzymes can alter steroid composition post-defaecation.

Objectives: This study investigated changes in faecal glucocorticoid (fGCM), androgen (fAM) and progestagen (fPM) metabolite concentrations in faeces of a male and female African elephant (Loxodonta africana) post-defaecation and the influence of different faeces-drying regimes.

Method: Subsamples of fresh faeces were frozen after being dried in direct sun or shade for 6, 20,24, 48 and $72 \mathrm{~h}$ and 7 and 34 days. A subset of samples for each sex was immediately frozen as controls. Faecal hormone metabolite concentrations were determined using enzyme immunoassays established for fGCM, fAM and fPM monitoring in male and female African elephants.

Results: Hormone metabolite concentrations of all three steroid classes were stable at first, but changed distinctively after $20 \mathrm{~h}$ post-defaecation, with fGCM concentrations decreasing over time and fPM and fAM concentrations steadily increasing. In freeze-dried faeces fGCM concentrations were significantly higher than respective concentrations in sun-dried material, which were in turn significantly higher than fGCM concentrations in shade-dried material. In contrast, fAM concentrations were significantly higher in sun- and shade-dried faeces compared to freeze-dried faeces. Higher fPM concentrations were also found in air-dried samples compared to lyophilised faeces, but the effect was only significant for sun-dried material.

Conclusion: The revealed time restriction for collecting faecal material for hormone monitoring from elephants in the wild should be taken into account to assure reliable and comparable results. However, if logistics allow a timely collection, non-invasive hormone measurement remains a powerful and reliable approach to provide information about an elephant's endocrine status.

\section{Introduction}

Evaluation of hormone concentrations is an accepted tool for monitoring reproductive functions and perception of stressors (Ganswindt et al. 2012a). Hormones are involved in almost all bodily functions, for example regulating reproduction, restoring homeostasis and behaviour expression (Touma \& Palme 2005; Wasser, Risler \& Steiner 1988). The endocrine system is an inner body communication system, with hormones being secreted by gonadal and adrenocortical tissue in response to stimuli and carried by the blood to target sites, where they perform their functions (Busso \& Ruiz 2011).

Apart from blood, hormones and their metabolites are present in a number of additional biological matrices, such as saliva, urine and faeces. Hormone metabolites in these matrices can be used as an alternative for hormone monitoring (Hodges, Brown \& Heistermann 2010; Sheriff et al. 2011). Determining concentrations of hormones or their metabolites using these matrices, commonly known as minimal or non-invasive hormone monitoring, has become a common approach for assessing endocrine correlates, especially in wildlife species (Ganswindt et al. 2012a).

Faeces is a matrix for non-invasive hormone monitoring. Sample collection following defaecation is comparatively simple, quick and allows the collector to maintain a distance from the study

How to cite this article: Webber, J.T, Henley, M.D, Pretorius, Y, Somers, M.J, Ganswindt, A. 2018, 'Changes in African Elephant (Loxodonta africana) faecal steroid concentrations post-defaecation', Bothalia 48(2), a2312. https://doi.org/10.4102/abc.v48i2.2312 Copyright: @ 2018. The Authors. Licensee: AOSIS. This work is licensed under the Creative Commons Attribution License. 
animal. This collection method avoids the need for capture or restraint of an animal and thus facilitates feedback-free sampling (Ganswindt et al. 2012a; Hulsman et al. 2011). In many species, faecal hormone metabolite concentrations represent the cumulative secretion and elimination of circulating hormones related to gastrointestinal transit time (Gesquiere et al. 2014; Hulsman et al. 2011; Touma \& Palme 2005). Faecal hormone metabolite monitoring is thus less sensitive to pulsatile and episodic fluctuations in hormone secretions (Touma \& Palme 2005).

Faecal steroid analysis does, however, come with its challenges; for example hormone metabolites might not be evenly distributed throughout a faecal sample, necessitating thorough mixing of sample material after collection (Millspaugh \& Washburn 2004; Wasser et al. 1996). When using non-invasive techniques, researchers need to be aware of species- and sex-specific differences in steroid metabolism (Schwarzenberger 2007; Touma et al. 2003). Potential matrixspecific effects on hormone metabolite concentrations related to processing and storage of samples also need to be considered (Hunt \& Wasser 2003; Millspaugh \& Washburn 2004). Rigorous validation of assays, storage and processing techniques are required to ensure reliable results in analysing faecal steroid concentrations.

Faecal bacteria enzymes can compromise the reliability of steroid monitoring by breaking down steroids and altering metabolite concentrations post-defaecation (Mostl et al. 1999; Washburn \& Millspaugh 2002). To halt these metabolic processes, a faecal sample must be frozen or the water removed (Palme 2005). Standardised freezing protocols for faecal material collected immediately after defaecation have been established to control for these confounding effects (Hulsman et al. 2011). Such an approach can easily be applied in a controlled environment, like zoological gardens, but immediate freezing of faeces after defaecation can be challenging when working under field conditions. As a result, a number of studies have frozen collected material within a standardised period following defaecation (Ahlers et al. 2012; Ganswindt et al. 2010a) or opted for alternative methods such as drying the material as soon as possible to prevent bacterial alteration of hormone concentrations (Terio et al. 2002). Although quite effective for some species (Kalbitzer et al. 2015; Shutt, Setchell \& Heistermann 2012), alternative, more field-friendly methods involving wet-faeces extraction have not often been considered for elephants, as intra-sample variation in faecal hormone concentrations appears extremely high, but can be substantially reduced when extracting steroids from dried faecal matter (Wasser et al. 1996). Thus, freezing unpreserved African elephant faecal samples under standardised settings with subsequent freeze-drying of collected material still seems the most reliable method for accurate steroid measurements (Hunt \& Wasser 2003).

Variation in steroid metabolite concentrations post-defaecation has been examined for a few species (Khan et al. 2002; Terio et al. 2002). For example, in cheetahs (Acinonyx jubatus), progestagen metabolite concentrations increased over time in unpreserved faecal matter, whereas glucocorticoid metabolite concentrations decreased and androgen metabolite concentrations were not affected by the drying process (Terio et al. 2002).

Non-invasive hormone monitoring is a well-established method for African elephants (Loxodonta africana), with Poole et al. (1984) using this technique in the early 1980s for monitoring steroid concentrations in free-ranging animals. Since then there have been many studies using this methodology to monitor faecal hormone metabolites in captive (e.g. Brown 2000; Brown et al. 2007; Ganswindt et al. 2002, 2003) and free-ranging African elephants (e.g. Ahlers et al. 2012; Ganswindt, Heistermann \& Hodges 2005; Ganswindt et al. 2010a, 2010b; Viljoen et al. 2008). Ahlers et al. (2012) established an enzyme immunoassay (EIA) for determining alterations in faecal progestagen metabolite (fPM) concentrations, whereas the EIAs for measuring faecal androgen (fAM) and glucocorticoid metabolite (fGCM) concentrations in captive and wild African elephants were established by Ganswindt et al. (2002, 2003, 2005, 2010a) and Viljoen et al. 2008.

To our knowledge, post-defaecation changes in steroid metabolite concentrations and potential steroid-class-related differences in unpreserved elephant faeces have not been examined. Such understanding would assist in establishing a logistical setting for cross-sectional sampling of free-ranging elephants. Non-invasive hormone monitoring could be optimised as a tool for evaluating the impact of management interventions including contraception and translocation (Viljoen et al. 2008; Wasser et al. 1996).

The project objectives included investigating changes in fGCM, fAM and fPM concentrations in male and female African elephant faeces over time after defaecation. In addition, differences in steroid metabolite concentrations in freeze- and air-dried faeces were evaluated, with air-dried material fully dried under either full sun or shade conditions.

\section{Research method and design Study animals}

In April 2017, fresh faecal material was collected from two African elephants, a 20-year-old male and a 15-year-old female, housed at Adventures with Elephants, South Africa ( $24^{\circ} 46^{\prime} 53.8^{\prime \prime}$ S; $\left.27^{\circ} 57^{\prime} 03.3^{\prime \prime} \mathrm{E}\right)$. The elephants' diet was natural vegetation in the area (mixed bushveld) supplemented with bana grass, fruit and vegetables, oats, lucerne and self-made game pellets. Water was available ad libitum.

\section{Sample collection}

Faecal material was collected using nitrile gloves immediately after defaecation from the middle of a bolus to avoid contamination by urine or debris (Ganswindt et al. 2002; Hodges et al. 2010). Faeces was collected from several boluses, thoroughly mixed and split into 69 samples of approximately 
$12 \mathrm{~g}$ each. Samples were immediately frozen in plastic vials and stored at $-20^{\circ} \mathrm{C}$ until further processing.

\section{Alteration of steroid concentration post- defaecation experiment}

Thirty-six samples from each elephant were thawed and triplicates refrozen after being dried in the sun or shade for 6 , $20,24,48,72 \mathrm{~h}$ or 1 week. Sun-dried samples were placed in full sun between 08:00 and 16:00 and placed undercover overnight to avoid dew contamination. Shade-dried samples were placed in a cardboard box with holes in the top, which prevented sunlight exposure but allowed air to move freely around the sample. The three samples from each individual that remained frozen represented $t=0$. Subsequently, all frozen material was lyophilised at the end of the experiment.

\section{Faecal matrix drying experiment}

After thawing 20 samples from each individual, 10 subsamples were fully dried in either full sun or shade (same conditions as described above). All samples were mixed daily to promote even drying. Air-dried samples were weighed every $24 \mathrm{~h}$ and considered dry when subsequent weights differed by $\leq 0.01 \mathrm{~g}$. This process took a maximum of 34 days. A subset of 10 samples for each elephant remained frozen and were used as controls. Subsequently, all frozen material was lyophilised at the end of the experiment.

\section{Hormone extraction}

All lyophilised faecal material was pulverised and sieved through a mesh strainer to remove undigested material (Fiess, Heistermann \& Hodges 1999). Between $0.50 \mathrm{~g}$ and $0.60 \mathrm{~g}$ of dry faecal powder (exact weight noted) was extracted by adding $3 \mathrm{ml}$ of $80 \%$ ethanol in distilled water. Suspensions were vortexed for $15 \mathrm{~min}$ and then centrifuged for $10 \mathrm{~min}$ at 1500 g. Supernatants were stored at $-20^{\circ} \mathrm{C}$ until hormone analysis (Ganswindt et al. 2014).

\section{Hormone analysis}

Faecal steroid extracts were measured for fGCM concentrations, using established EIAs for fGCM monitoring in male and female African elephants (Ganswindt et al. 2003; Viljoen et al. 2008), fAM concentrations in African elephant bulls (Ganswindt et al. 2002) and fPM concentrations in female African elephants (Ahlers et al. 2012; Szdzuy et al. 2006). Respective EIAs used antibodies against 11-oxoetiocholanalone (detecting fGCMs with a $5 \beta 3 \alpha$-ol-11-one structure), epiandrosterone (detecting $5 \alpha$-androstanes) and $5 \alpha$-pregnan3 $\beta$-ol-20-on (detecting 20-oxo-pregnanes). Assay methodologies used were as published by Ganswindt et al. (2002) and the analyses took place at the Endocrine Research Laboratory, University of Pretoria, South Africa. Sensitivities (90\% binding) of the assays were $1.2 \mathrm{ng} / \mathrm{g}$ dry faeces (DW) for fGCM, $24 \mathrm{ng} / \mathrm{g}$ DW for fAM and $18 \mathrm{ng} / \mathrm{g}$ DW for the fPM EIA, respectively. Intra-assay coefficients of variation, determined by repeated measurements of high and low value quality controls, were $3.3 \%$ and $5.6 \%$ for fGCM, $4.5 \%$ and $5.5 \%$ for fAM, and $2.5 \%$ and $5.3 \%$ for fPM measurements. Inter-assay coefficients of variation were $4.3 \%$ and $6.8 \%$ for fGCM, $6.3 \%$ and $9.2 \%$ for fAM, and $4.6 \%$ and $7.8 \%$ for the fPM EIA.

\section{Data analysis}

The relative change in steroid concentration post-defaecation for each subsample was calculated using the mean steroid concentration determined at $t=0$ as $100 \%$. Differences in steroid concentration between samples stored at $t=0 \mathrm{~h}$ and 6-168 h post-defaecation were examined descriptively as well as by one-way repeated measures ANOVA, followed by post hoc analysis using a Bonferroni $t$-test, with application of the Bonferroni correction. Differences in steroid concentrations between drying treatments were examined by KruskalWallis one-way ANOVA on ranks followed by post hoc pairwise comparisons using Dunn's method. The statistical analyses were performed using the software programme Sigma Plot 12.5. Statistical significance was assumed when $p<0.05$. Data are presented as means \pm SD, medians and ranges where applicable.

\section{Ethical considerations}

All applicable international, national and institutional guidelines for the care and use of animals were followed during faecal sample collection. The study was conducted with the approval of the Centre for Wildlife Management Research Committee (10-04-16).

\section{Results}

\section{Time-related change of fGCM concentrations post-defaecation}

Dried faecal samples from the male and female African elephant showed a distinct overall decrease in mean fGCM concentrations of about $\sim 80 \%$ after $168 \mathrm{~h}$ (see Figures 1a and 1c). Mean fGCM concentrations from males initially increased (up to $23 \%$ for shade- and 5\% for sun-dried samples) before declining until the end of the experiment (Figure 1a). Similarly, mean fGCM concentrations of female samples dried in the sun slightly increased at the beginning before declining continuously thereafter. However, fGCM concentrations from female faecal material dried in the shade followed no clear trend for the first $24 \mathrm{~h}$ before starting to decrease (Figure 1c).

Male fGCM concentrations for material dried in the shade as well as in the sun were significantly different between 0 and 48-168 h post-defaecation samples (shade: $F=120.11$, $p<0.001$, post hoc analysis: $p<0.001$ for 48,72 and $168 \mathrm{~h}$, respectively; sun: $F=41.91, p<0.001$, post hoc analysis: $p<0.001$ for 48,72 and $168 \mathrm{~h}$, respectively). For females, fGCM concentrations were significantly different for samples dried in the shade between 0 and $72-168 \mathrm{~h}$ post-defaecation $(F=14.86, p<0.001$, post hoc analysis: $p<0.001$ for 72 and $168 \mathrm{~h}$, respectively). Female fGCM concentrations from samples dried in the sun showed a significant difference between 0 and $48-168$ h post-defaecation samples $(F=21.84, p<0.001$, post hoc analysis: $p<0.001$ for 48,72 and $168 \mathrm{~h}$, respectively). 

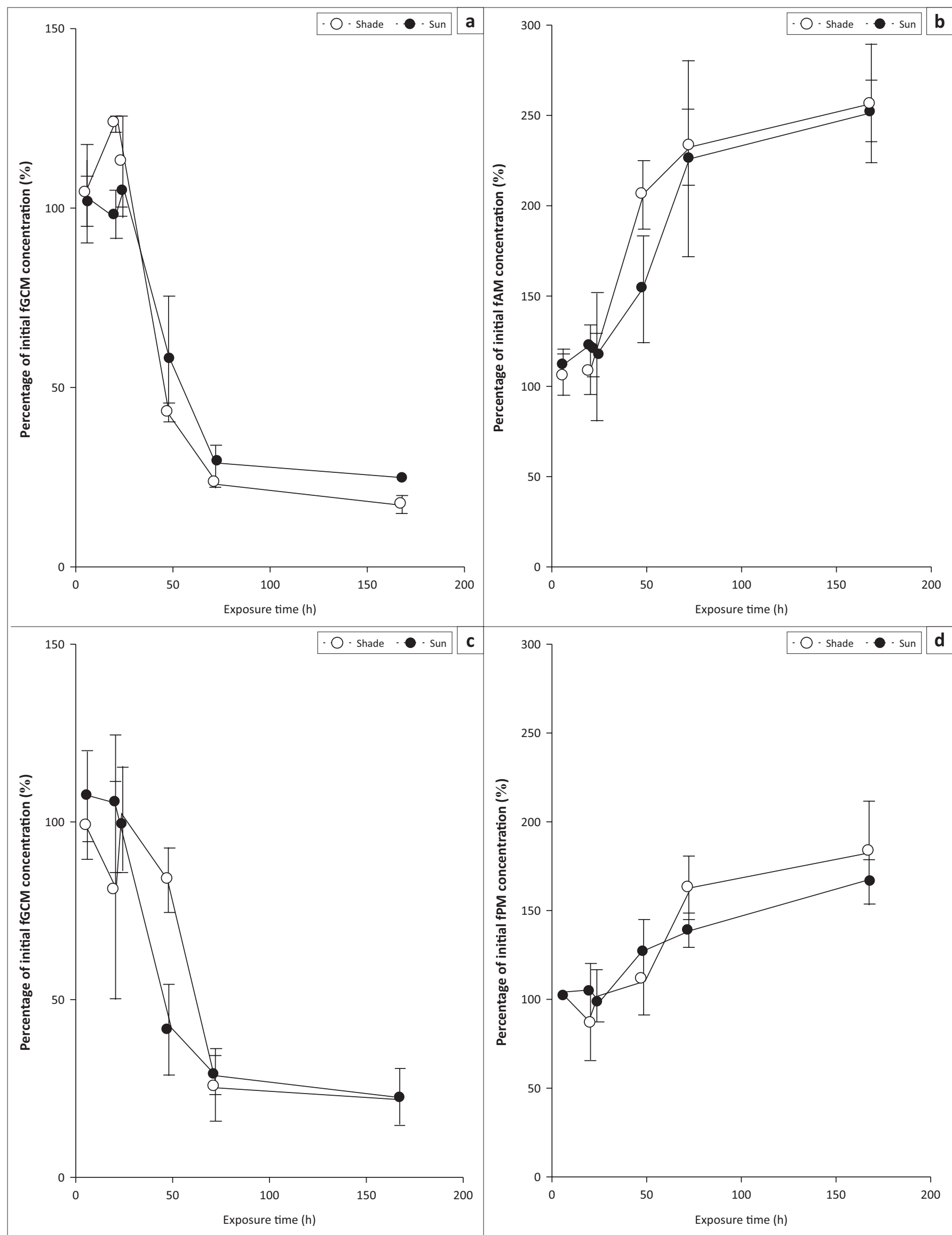

FIGURE 1: Relative change (\%) of steroid metabolite concentrations in African elephant faeces (male: fGCM [a], fAM [b]; female: fGCM [c], fPM [d]) over time (6, 20, 24, 48,72 and $168 \mathrm{~h}$ after defaecation) for sample sets dried in the sun (black dots) or in the shade (white dots). Alterations in faecal steroid metabolite concentrations of sample triplicates are expressed as mean \pm standard deviation for each time point. fGCM, faecal glucocorticoid metabolite; fAM, faecal androgen metabolite; fPM, faecal progestagen metabolite. 


\section{Time-related change of fAM and fPM concentrations post-defaecation}

For both drying regimes, fAM concentrations in faecal matter of males continuously increased from $6 \mathrm{~h}$ post-defaecation, reaching a maximum increase of $\sim 150 \%$ after $168 \mathrm{~h}$ postdefaecation (see Figure 1b). A significant difference in fAM concentrations for material dried in the shade was found between 0 and $48-168 \mathrm{~h}$ post-defaecation samples $(F=29.05$, $p<0.001$, post hoc analysis: $p<0.001$ for 48,72 and $168 \mathrm{~h}$, respectively). Faeces dried in the sun showed a significant difference in fAM concentrations between 0 and 72-168 h post-defaecation samples $(F=21.60, p<0.001$, post hoc analysis: $p<0.001$ for 72 and $168 \mathrm{~h}$, respectively).

Mean fPM concentrations initially decreased (up to $14 \%$ for shade- and $2 \%$ for sun-dried samples) before continuously increasing until the end of the experiment (see Figure 1d). Female fPM concentrations for material dried in the shade as well as in the sun were significantly different between 0 and $72-168 \mathrm{~h}$ post-defaecation samples (shade: $F=10.80$, $p<0.001$, post hoc analysis: $p=0.013$ and $p<0.001$ for 72 and 168 h, respectively; sun: $F=15.11, p<0.001$, post hoc analysis: $p=0.012$ and $p<0.001$ for 72 and $168 \mathrm{~h}$, respectively).

\section{Drying times under different regimes}

The time to reach complete dryness varied for samples within subsets. Air-dried samples in the sun were completely dry within 11-16 days (male) and 9-17 days (female), with a median time of 11 days for both sexes. Similarly, air-dried samples in the shade were completely dry within 26-33 days (male) and 29-34 days (female), with a median time of 30 days for both sexes.

\section{Differences in steroid concentrations of samples dried under different regimes}

Concentrations of fGCMs in male and female faecal matter differed significantly between the three treatment groups (male: $H=25.8, \mathrm{df}=2, p=0.001$; female: $H=24.9$, $\mathrm{df}=2$, $p=0.001$; Figure 2a), with fGCM concentrations of freezedried samples being significantly higher (male: $0.44 \mu \mathrm{g} / \mathrm{g}$ $\mathrm{DW} \pm 0.05[$ mean $\pm \mathrm{SD}$ ]; female: $0.75 \mu \mathrm{g} / \mathrm{g} \mathrm{DW} \pm 0.10$ ) compared to faecal matter dried in the sun (male: $0.05 \mu \mathrm{g} / \mathrm{g}$ $\mathrm{DW} \pm 0.01, Q=3.6, p<0.05$; female: $0.11 \mu \mathrm{g} / \mathrm{g} \mathrm{DW} \pm 0.02$, $Q=2.4, p<0.05$ ) and shade (male: $0.03 \mu \mathrm{g} / \mathrm{g} \mathrm{DW} \pm 0.003$, $Q=7.2, p<0.05$; female: $0.05 \mu \mathrm{g} / \mathrm{g} \mathrm{DW} \pm 0.01, Q=4.9$, $p<0.05)$. Furthermore, fGCM concentrations of male and female samples that were dried in the sun were significantly higher than fGCM concentrations of material dried in the shade (male: $Q=3.6, p<0.05$; female: $Q=2.4, p<0.05$ ).

Male fAM concentrations differed significantly between treatments $(H=22.7, \mathrm{df}=2, p=0.001$; Figure $2 \mathrm{~b})$, with concentrations in freeze-dried samples being significantly lower $(1.26 \mu \mathrm{g} / \mathrm{g} \mathrm{DW} \pm 0.25)$ compared to concentrations in faecal matter dried in the sun $(3.46 \mu \mathrm{g} / \mathrm{g} \mathrm{DW} \pm 0.52, Q=4.1$, $p<0.05)$ and in the shade $(4.67 \mu \mathrm{g} / \mathrm{g} \mathrm{DW} \pm 1.14, Q=6.7$, $p<0.05)$, respectively. Concentrations of fAMs in faecal samples dried in the sun and dried in the shade did not differ significantly $(Q=2.6, p>0.05)$.

Female fPM concentrations differed significantly between treatment groups $(H=19.9, \mathrm{df}=2, p=0.001$; Figure $2 b)$, with fPM concentrations of freeze-dried samples being significantly lower $(2.56 \mu \mathrm{g} / \mathrm{g} \mathrm{DW} \pm 0.17)$ compared to faecal matter dried in the sun $(6.37 \mu \mathrm{g} / \mathrm{g} \mathrm{DW} \pm 0.86 ; Q=4.4$, $p<0.05)$. In contrast, freeze-dried fPM concentrations were

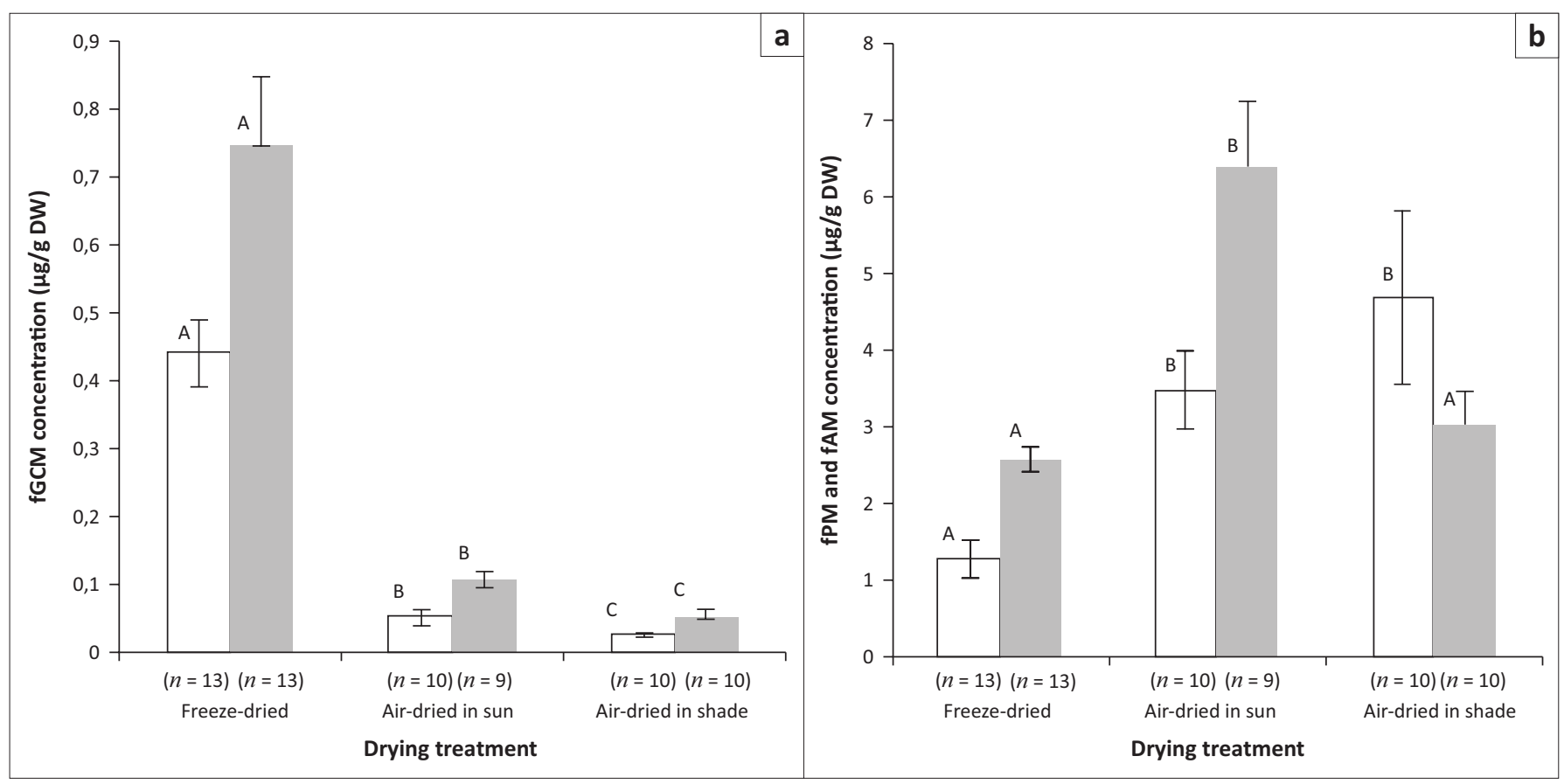

FIGURE 2: Bar plots of African elephant faecal steroid metabolite concentrations (mean \pm SD) for male (white bars) and female (grey bars) samples completely dried under three different regimes (freeze-drying, air-dried in the sun, air-dried in the shade) for subsequent steroid extraction. Faecal steroid metabolite concentrations (fGCM [a] and fAM [b]) were measured in the male and [fGCM (A) and fPM (B)] female samples, respectively. Statistical differences in faecal steroid metabolite concentrations between different drying regime groups for the four different data sets (male fGCM, male fAM, female fGCM and female fPM concentrations) are indicated by different superscripts. 
not different to fPM concentrations of faecal matter dried in the shade $(3.03 \mu \mathrm{g} / \mathrm{g} \mathrm{DW} \pm 0.41 ; Q=1.37, p>0.05)$. Concentrations of fPMs from sun-dried samples were also significantly higher than respective concentrations of material dried in the shade $(Q=3.04, p<0.05)$.

\section{Discussion}

In this study, we examined the rate of change in glucocorticoid, androgen and progestagen metabolite concentrations in the faeces of two African elephants, a male and female, when dried under natural conditions.

Our findings that fGCM concentrations decreased over time are in agreement with findings reported by Hulsman et al. (2011). They found a continuous decrease in fGCM concentrations for up to $32 \mathrm{~h}$ after defaecation in the drying faecal matter of male and female brown hyaena (Hyaena brunnea), using the same EIA. In addition, Lexen et al. (2008) demonstrated a decrease in glucocorticoid concentrations in the faeces of sheep (Austrian mountain sheep) for up to $24 \mathrm{~h}$ post-defaecation, again using the same EIA (detecting fGCMs with a $5 \beta-3 \alpha$-ol-11-one structure) for analysis. Based on these findings it seems possible that glucocorticoid metabolites with a $5 \beta-3 \alpha$-ol-11-one structure are a common and host-independent product of bacterial alteration in mammal faeces. At least for the African elephant, one of the major glucocorticoid metabolites excreted into faeces is $5 \beta$-androstane-3 $\alpha, 11 \beta$-diol-17-one (Ganswindt et al. 2003). However, further analyses including high-performance liquid chromatography (HPLC) and gas chromatography-mass spectrometry (GC/MS) would be necessary to examine the presence and relative abundance of glucocorticoid metabolites with a $5 \beta-3 \alpha-o l-11$-one structure in other mammalian faeces.

Specificity of the antibody used cannot be underestimated as demonstrated in a study by Lexen et al. (2008), who showed the above-mentioned decrease in fGCM concentrations in sheep faeces post-defaecation when using the EIA detecting fGCMs with a $5 \beta-3 \alpha$-ol-11-one structure. In contrast, they found a similarly distinct increase in fGCM concentrations in the same faecal matter when using an EIA detecting 11, 17 dioxoandrostanes. Thus, the use of different assays for determining respective changes in fGCM concentrations makes the predictability of expected changes difficult, as it can result in a distinct increase in fGCM concentrations, as demonstrated for sheep (Lexen et al. 2008) and African buffalo (Syncerus caffer; Ganswindt et al. 2012b), or in a significant decrease in fGCM concentrations as shown for African elephant (this study) and brown hyaena (Hulsman et al. 2011). In some cases fGCM concentrations stay relatively stable over time, as seen in Nile crocodile (Crocodylus niloticus), jaguar (Panthera onca), or leopard (Panthera pardus; Ganswindt et al. 2014; Mesa-Cruz, Brown \& Kelly 2014; Webster 2017). However, opposite trends in fGCM concentrations post-defaecation can even be found when using the same EIA in various species. In contrast to Lexen's sheep results, Laver et al. (2012) demonstrated a decline in fGCM concentrations within the first $2 \mathrm{~h}$ post-defaecation for banded mongooses (Mungos mungo) when using the EIA detecting 11,17 dioxoandrostanes.

Comparatively few studies looked at respective quantitative changes in faecal reproductive hormone metabolite concentrations post-defaecation. However, our findings of increasing fPM concentrations in drying faeces of a male and female African elephant are in agreement with results of a study on baboons (Papio cynocephalus), where fPM concentrations also increased after $6 \mathrm{~h}$ post-defaecation using a 4-pregnen-3,20-dione 3-CMO assay (Wasser et al. 1988). Similarly, higher fPM concentrations were found in unpreserved cheetah samples drying in a solar oven compared to samples that were freeze-dried, also using a progesterone assay (Terio et al. 2002). Likewise, fAM concentrations in African elephant faeces also increased post-defaecation, but we could not find another study that had already examined time-sequence alterations in fAM concentration post-defaecation. The closest was the study by Terio et al. (2002), where no significant differences in fAM concentrations between oven- and freeze-dried cheetah faecal samples were found when analysing the material with a testosterone assay. Again, further chromatographic and mass-spectrometric analyses are required to determine the presence and relative abundance of respective fPMs and fAMs in African elephant and other mammalian faeces. This would determine the link between hormone metabolites actually present and the specificity of the antibodies used. In this regard, it should be further considered that diet of captive and free-ranging individuals might vary considerably, which likely affects their gastrointestinal microbiome. Such differences in the gastrointestinal microbiome could also influence the presence and relative abundance of steroid metabolites, as bacteria are thought to be responsible for steroid metabolism in faecal material.

When faecal matter dries under natural conditions, the duration until it is fully dry depends, apart from size, texture and water content of the sample, on the local weather conditions, mainly the number of hours the material is exposed to sunlight and no rain. Consequently, a longer drying time provides bacteria, at least theoretically, more time to alter the steroid composition in the faecal matrix (Galama, Graham \& Savage 2004). Our results showed that fGCM concentrations in freeze-dried African elephant faeces were significantly higher than steroid concentrations in sundried material, which were in turn significantly higher than fGCM concentrations in shade-dried material. In contrast, findings from Mesa-Cruz et al. (2014) showed that jaguar faeces exposed to sun and shade drying treatments within the wet or dry season did not reveal any differences in fGCM concentrations between treatments exposed for a period of 5 days. The authors explained this by the possible inability of UV rays to penetrate the sample vials used, resulting in only the top few micrometres of faecal material being exposed to sunlight for the five days of the experiment (Mesa-Cruz et al. 2014). For African elephants, the effect of more drying hours appears relevant especially for fGCM concentrations, as no 
significant difference in fAM concentrations could be found between sun- and shade-dried material, although the trend of higher overall steroid concentrations with longer drying time (shade treatment) still exists. Comparatively higher fPM concentrations were also found in air-dried samples from African elephants compared to lyophilised faeces, but the effect was most prominent and only significant for sun-dried material. Our results for reproductive steroids are in agreement with findings in a study on cheetahs, where unpreserved faeces that were wet comparatively longer (oven-dried) also showed significantly higher fPM concentrations compared to samples that were freeze-dried (Terio et al. 2002).

\section{Conclusion}

The results of our study suggest that steroid metabolites in elephant faeces start changing distinctively after $20 \mathrm{~h}$ postdefaecation, with opposite trends for fGCMs on the one hand, and fPMs and fAMs on the other. This comparatively narrow time window of about a day should be taken into account when collecting material from animals in the wild, especially when collection takes place without observing the actual animal defecating, to assure reliable and comparable results. However, if logistics allow collection of faecal matter within a day, non-invasive hormone measurement remains a powerful and reliable approach to provide information about an elephant's endocrine status.

\section{Acknowledgements}

We thank Elephants Alive and the Eugene Marais Chair of Wildlife Management for their financial contributions. We thank Sean Hensman and his team at Adventures with Elephants for granting access to their elephants. We also thank Mrs Stefanie Ganswindt for expert help with laboratory techniques.

\section{Competing interests}

We have no competing interests with regard to the writing of this article.

\section{Authors' contributions}

J.T.W. was the principal investigator and responsible for study development, sample collection, data analysis, and writing of the article; M.D.H. and Y.P. were responsible for study development and contributing to the manuscript. M.J.S. was responsible for development of the manuscript. A.G. was the supervisor and made contribution to study development, data analysis and development of the manuscript.

\section{References}

Ahlers, M.J., Ganswindt, A., Münscher, S. \& Bertschinger, H.J., 2012, 'Fecal 20-oxopregnane concentrations in free-ranging African elephants (Loxodonta africana) treated with porcine zona pellucida vaccine', Theriogenology $78(1), 77-85$ https://doi.org/10.1016/j.theriogenology.2012.01.023

Brown, J.L., 2000, 'Reproductive endocrine monitoring of elephants: An essential tool for assisting captive management', Zoo Biology 367, 347-367. https://doi.org/ 10.1002/1098-2361(2000)19:5<347::AID-ZOO6>3.0.CO;2-V
Brown, J.L., Somerville, M., Riddle, H.S., Keele, M., Duer, C.K. \& Freeman, E.W., 2007 'Comparative endocrinology of testicular, adrenal and thyroid function in captive 'Asian and African elephant bulls', General and Comparative Endocrinology 151(2), 153-162. https://doi.org/10.1016/j.ygcen.2007.01.006

Busso, J.M. \& Ruiz, R.D., 2011, 'Excretion of steroid hormones in rodents: An overview on species differences for new biomedical animal research models', in E. DiamantiKandara (ed.), Contemporary aspects of endocrinology, pp. 375-396, InTech, Cordoba.

Fiess, M., Heistermann, M. \& Hodges, J.K., 1999, 'Patterns of urinary and fecal steroid excretion during the ovarian cycle and pregnancy in the African elephant (Loxodonta africana)', General and Comparative Endocrinology 115(1), 76-89. https://doi.org/10.1006/gcen.1999.7287

Galama, W.T., Graham, L.H. \& Savage, A., 2004, 'Comparison of fecal storage methods for steroid analysis in black rhinoceroses (Diceros bicornis)', Zoo Biology 23(4), 291-300. https://doi.org/10.1002/zoo.20017

Ganswindt, A., Brown, J.L., Freeman, E.W., Kouba, A.J., Penfold, L.M., Santymire, R.M. et al., 2012a, 'International Society for Wildlife Endocrinology: The future of endocrine measures for reproductive science, animal welfare and conservation biology', Biology Letters 8(5), 695-697. https://doi.org/10.1098/rsbl.2011.1181

Ganswindt, A., Heistermann, M., Borragan, S. \& Hodges, J.K., 2002, 'Assessment of testicular endocrine function in captive African elephants by measurement of
urinary and fecal androgens', Zoo Biology 21(1), 27-36. https://doi.org/10.1002/ urinary and
zoo.10034

Ganswindt, A., Heistermann, M. \& Hodges, K., 2005, 'Physical, physiological, \& behavioral correlates of musth in captive African elephants (Loxodonta africana)', Physiological and Biochemical Zoology 78(4), 505-514. https://doi.org/10.1086/ 430237

Ganswindt, A., Muenscher, S., Henley, M., Henley, S., Heistermann, M., Palme, R. et al., 2010a, 'Endocrine correlates of musth and the impact of ecological and social factors in free-ranging African elephants (Loxodonta africana)', Hormones and Behavior 57(4-5), 506-514. https://doi.org/10.1016/j.yhbeh.2010.02.009

Ganswindt, A., Münscher, S., Henley, M., Palme, R., Thompson, P. \& Bertschinger, H.J. $2010 \mathrm{~b}$, 'Concentrations of faecal glucocorticoid metabolites in physically injured free-ranging African elephants Loxodonta africana', Wildlife Biology 16, 323-332. https://doi.org/10.2981/09-081

Ganswindt, A., Palme, R., Heistermann, M., Borragan, S. \& Hodges, J.K., 2003, 'Noninvasive assessment of adrenocortical function in the male African elephan (Loxodonta africana) and its relation to musth', General and Comparative Endocrinology 134(2), 156-166. https://doi.org/10.1016/S0016-6480(03)00251-X

Ganswindt, A., Tordiffe, A., Stam, E., Howitt, M. \& Jori, F., 2012b, 'Determining adrenocortical activity as a measure of stress in African buffalo (Syncerus caffer) based on faecal analysis', African Zoology 47(2), 261-269. https://doi.org/ 10.3377/004.047.0211

Ganswindt, S.B., Myburgh, J.G., Cameron, E.Z. \& Ganswindt, A., 2014, 'Non-invasive assessment of adrenocortical function in captive Nile crocodiles (Crocodylus
niloticus)', Comparative Biochemistry and Physiology - Part A: Molecular and niloticus)', Comparative Biochemistry and Physiology - Part A: Molecular and
Integrative Physiology 177, 11-17. https://doi.org/10.1016/j.cbpa.2014.07.013

Gesquiere, L.R., Ziegler, T.E., Chen, P.A., Epstein, K.A., Alberts, S.C. \& Altmann J., 2014 'Measuring fecal testosterone in females and fecal estrogens in males: Comparison of RIA and LC/MS/MS methods for wild baboons (Papio cynocephalus)', General and Comparative Endocrinology 204, 141-149. https://doi.org/10.1016/j.ygcen. and Comparative

Hodges, J.K., Brown, J.L. \& Heistermann, M., 2010, 'Assessing physiological status', in D.G. Kleiman, K.V. Thompson \& C.K. Baer (eds.), Wild mammals in captivity, pp. 447-467, The University of Chicago Press, Chicago, IL

Hulsman, A., Dalerum, F., Ganswindt, A., Muenscher, S., Bertschinger, H.J. \& Paris, M., 2011, "Non-invasive monitoring of glucocorticoid metabolites in brown hyaena (Hyaena brunnea) feces', Zoo Biology 30, 451-458. https://doi.org/10.1002/ zoo.20325

Hunt, K.E. \& Wasser, S.K., 2003, 'Effect of long-term preservation methods on fecal glucocorticoid concentrations of grizzly bear and African elephant', Physiological and Biochemical Zoology 76(6), 918-928. https://doi.org/10.1086/380209

Kalbitzer, U., Heistermann, M., Cheney, D., Seyfarth, R. \& Fischer, J., 2015, 'Social behavior and patterns of testosterone and glucocorticoid levels differ between male chacma and Guinea baboons', Hormones and Behavior 75, 100-110. https:// doi.org/10.1016/j.yhbeh.2015.08.013

Khan, M.Z., Altmann, J., Isani, S.S. \& Yu, J., 2002, 'A matter of time: Evaluation the storage of fecal samples for steroid analysis', General and Comparative Endocrinology 128(1), 57-64. https://doi.org/10.1016/S0016-6480(02)00063-1

Laver, P.N., Ganswindt, A., Ganswindt, S.B. \& Alexander, K.A., 2012, 'Non-invasive monitoring of glucocorticoid metabolites in banded mongooses (Mugos mungo) in response to physiological and biological challenges', General and Comparative Endocrinology 179(2), 178-183. https://doi.org/10.1016/j.ygcen.2012.08.011

Lexen, E., El-Bahr, S.M., Sommerfeld-Stur, I., Palme, R. \& Möstl, E., 2008, 'Monitoring the adrenocortical response to disturbances in sheep by measuring glucocorticoid metabolites in the faeces', Veterinary Medicine Austria 95(3-4), 64-71.

Mesa-cruz, J.B., Brown, J.L. \& Kelly, M.J., 2014, 'Effects of natural environmental conditions on faecal glucocorticoid metabolite concentrations in jaguars (Panthera onca) in Belize', Conservation Physiology 2, 1-10. https://doi.org/10.1093/conphys/ cou039.Introduction

Millspaugh, J.J. \& Washburn, B.E., 2004, 'Use of fecal glucocorticoid metabolite measures in conservation biology research: Considerations for application and interpretation', General and Comparative Endocrinology 138(3), 189-199. https:// doi.org/10.1016/j.ygcen.2004.07.002

Mostl, E., Messmann, E., Bagu, E., Robia, C., Palme, R., Möstl, E. et al., 1999 'Measurement of glucocorticoid metabolite concentrations in faeces of domestic $\mathrm{org} / 10.1046 / \mathrm{j} .1439-0442.1999 .00256 . x$ 
Palme, R., 2005, 'Measuring fecal steroids: Guidelines for practical application', Annals of the New York Academy of Sciences 1046, 75-80. https://doi.org/10.1196/ annals.1343.007

Poole, J.H., Kasman, L.H., Ramsay, E.C. \& Lasley, B.L., 1984, 'Musth and urinary testosterone concentrations in the African elephant (Loxodonta africana)', Journal of Reproduction and Fertility 70, 255-260. https://doi.org/10.1530/jrf.0. 0700255

Schwarzenberger, F., 2007, 'The many uses of non-invasive faecal steroid monitoring in zoo and wildlife species', International Zoo Yearbook 41, 52-74. https://doi. org/10.1111/j.1748-1090.2007.00017.x

Sheriff, M.J., Dantzer, B., Delehanty, B. \& Palme, R., 2011, 'Measuring stress in wildlife: Techniques for quantifying glucocorticoids', Oecologia 166(4), 869-887. https:// doi.org/10.1007/s00442-011-1943-y

Shutt, K., Setchell, J.M. \& Heistermann, M., 2012, 'Non-invasive monitoring of physiological stress in the Western lowland gorilla (Gorilla gorilla gorilla) Validation of a fecal glucocorticoid assay and methods for practical application in the field', General and Comparative Endocriology 179, 167-177. https://doi org/10.1016/j.ygcen.2012.08.008

Szdzuy, K., Dehnhard, M., Strauss, G., Eulenberger, K. \& Hofer, H., 2006, 'Behavioural and endocrinological parameters of female African and Asian elephants (Loxodonta africana and Elephas maximus) in the peripartal period', International Zoo Yearbook 40, 41-50. https://doi.org/10.1111/j.1748-1090.2006.00041.x

Terio, K.A., Brown, J.L., Moreland, R. \& Munson, L., 2002, 'Comparison of different drying and storage methods on quantifiable concentrations of fecal steroids in the cheetah', Zoo Biology 21(3), 215-222. https://doi.org/10.1002/zoo.10036
Touma, C. \& Palme, R., 2005, 'Measuring fecal glucocorticoid metabolites in mammals and birds: The importance of validation', Annals of the New York Academy of Sciences 1046, 54-74. https://doi.org/10.1196/annals.1343.006

Touma, C., Sachser, N., Möstl, E. \& Palme, R., 2003, 'Effects of sex and time of day on metabolism and excretion of corticosterone in urine and feces of mice', Genera and Comparative Endocrinology 130(3), 267-278. https://doi.org/10.1016/S00166480(02)00620-2

Viljoen, J.J., Ganswindt, A., Palme, R., Reynecke, H.C., Du Toit, J.T. \& Langbauer, W.R., 2008 , 'Measurement of concentrations of faecal glucocorticoid metabolites in free-ranging African elephants within the Kruger National Park', Koedoe: African Protected Area Conservation and Science 50, 18-21. https://doi.org/10.4102/ koedoe.v50i1.129

Washburn, B.E. \& Millspaugh, J.J., 2002, 'Effects of simulated environmental conditions on glucocorticoid metabolite measurements in white-tailed deer feces', General and Comparative Endocrinology 127, 217-222. https://doi.org/ 10.1016/S0016-6480(02)00056-4

Wasser, S.K., Papageorge, S., Foley, C. \& Brown, J.L., 1996, 'Excretory fate of estradiol and progesterone in the African elephant (Loxodonta africana) and patterns of fecal steroid concentrations throughout the estrous cycle' General and Comparative Endocrinology 102(2), 255-262. https://doi.org/10.1006/gcen.1996.0067

Wasser, S.K., Risler, L. \& Steiner, R.A., 1988, 'Excreted steroids in primate feces ove the menstrual cycle and pregnancy', Biology of Reproduction 39(4), 862-872. https://doi.org/10.1095/biolreprod39.4.862

Webster, A.B., 2017, 'Validation of a non-invasive technique using faecal glucocorticoid metabolites to measure stress in leopards (Panthera pardus)', MSc thesis, University of Pretoria, South Africa. 